\title{
A fadiga intelectual - um século de investigação em Psicologia Escolar
}

BINET, Alfred e HENRI, Victor - LA FATIGUE INTELECTUELLE. Paris: Schleicher Freres, 1898, avec 90 figures et 3 planches hors texte.

A análise deste trabalho de Binet está inserida no projeto "A Psicologia do século XIX no contexto cultural baiano". Este trabalho tem por objetivo reafirmar a importância do estudo histórico da Psicologia e de sua contextualização, no sentido de mostrar, tanto aos psicólogos atuais quanto aos futuros, o percurso da ciência e as contribuições dos que nos precederam - afinal é sabido que, ao longo do tempo, há várias questões que permanecem. Os estudos sobre fadiga intelectual, realizados por Binet e Henri, deixam isso muito claro. Alfred Binet (1857-1911), psicólogo francês, é famoso como o autor do teste de avaliação de inteligência que leva o seu nome. Como o investigador psicológico que gerou experiências originais e resultados fascinantes, inclusive no campo da memória, Binet é quase desconhecido. Em 1898, publica com Victor Henri, o livro A Fadiga Intelectual, inaugurando a Biblioteca de Pedagogia e de Psicologia, com o objetivo de proporciona à Pedagogia os avanços recentes da Psicologia Experimental. Para os autores, não se trata de reformar a atual Pedagogia, mas de substituí-Ia por uma nova, baseada na observação e na experiência, devendo ser, antes de tudo, experimental, fundamentada em documentos metodicamente recolhidos e relacionados em detalhes e precisão. Os experimentos poderiam ser feitos tanto no laboratório quanto em escolas, individual ou coletivamente. Os autores lamentam que a Administração francesa, diferentemente da de outros países, a exemplo da Alemanha, Suécia e Dinamarca, se mostre pouco disposta a provocar ou mesmo em concordar com investigações experimentais.

O livro é composto por uma introdução, em dois capítulos, e duas partes principais, cada uma delas dedicada às repercussões fisiológicas e psicológicas do trabalho intelectual, totalizando 338 páginas. Vale destacar, a bibliografia consultada está relacionada ao longo do texto.

Na primeira parte da introdução está a análise das discussões que ocorreram na Academia de Medicina de Paris em 1886/7 com relação ao excesso de trabalho intelectual, que provocaram fOlie repercussão na imprensa. Por seu turno, a Academia de Medicina designou uma comissão para analisar o assunto. As conclusões, após terem sido votadas, foram enviadas ao Ministro da Instrução Pública. A leitura dos registros das reuniões realizadas sobre o tema revela que os critérios utilizados pelos médicos se baseavam em convicções pessoais, como a utilização de epítetos, avaliações superficiais de programas, crítica à duração das aulas, afirmações gratuitas e relatos de patologias supostamente a ela associadas, tais como: tuberculose, febre tifóide, cefaléia, lesões dentárias. Em suma, um torneio literário, em vez de uma discussão científica. As conclusões são vagas, sugerindo "simplificação de programas" ou "diminuição do tempo de aula".

O que a Academia de Medicina não fez, a ciência tentou fazer: de 1888 a 1898 cientistas franceses e, principalmente, alemães, estudaram em laboratórios e nas escolas, os efeitos do trabalho intelectual sobre o espírito e sobre o corpo, realizando estudos rigorosamente experimentais - não se discute teoria: observa-se, mede-se, pesa-se.

O segundo capítulo da introdução trata da definição do trabalho intelectual. Os autores ponderam que as palavras mudam de sentido a depender de como as pessoas as empregam e 
segundo as matérias às quais elas se aplicam. Em Psicologia, o termo trabalho intelectual, como o de inteligência, tem uma significação muito vaga. Assim, deve ser compreendido por trabalho intelectual toda espécie de trabalho que os alunos realizam na escola, seja durante a aula, seja durante o estudo. Neste caso, o trabalho intelectual se opõe ao trabalho físico, ao muscular, no qual os alunos se envolvem durante o recreio, em aulas de ginástica ou, ainda, em certas partes das aulas de arte manual. A distinção entre trabalho intelectual e trabalho físico é teoricamente simples. Todavia, em todo trabalho intelectual há uma parte de trabalho físico, e em todo trabalho físico há uma palie de trabalho intelectual. Entretanto, o que caracteriza o trabalho físico é o papel desempenhado pelos movimentos e pelo sistema muscular, enquanto que, no trabalho intelectual o que predomina é a concentração de atenção e o jogo da inteligência. Além disso, diz Binet, o trabalho intelectual é extremamente variável, podendo ser curto ou prolongado, voluntário ou automático, intenso ou moderado, e apresentar um grande número de graus intermediários. São as influências produzidas por um trabalho intelectual voluntário que interessam neste livro; com efeito, é o trabalho voluntário que é exigido dos alunos nas escolas e é este trabalho que produz os efeitos de fadiga mental que, ao aumentar de intensidade, são nocivos ao organismo inteiro. Dentre as principais formas de trabalho intelectual: o cálculo mental, que é considerado uma das melhores formas para obrigar alguém a realizar um esforço intelectual forte e intenso, tem a vantagem de permitir variar a dificuldade e, por conseqüência, a duração da tarefa; a segunda consiste na repetição de memória de uma série de números; e a terceira é a leitura.

Os autores classificam os efeitos produzidos pelo trabalho intelectual em dois grupos: efeitos fisiológicos e efeitos psicológicos. Os fisiológicos são os que produzem modificações nas funções fisiológicas do organismo, tais como a circulação, respiração, temperatura, alimentação, as secreções. Os efeitos psicológicos são aqueles produzidos pelo trabalho intelectual, fadiga da atenção de intensidade variável, que influencia diferentes funções intelectuais e morais. Todos estes efeitos serão mais ou menos acentuados segundo a duração e a intensidade do esforço mental.

A primeira parte é composta por sete capítulos que tratam, respectivamente, dos "Efeitos fisiológicos do trabalho intelectual" sobre:

- o coração: velocidade e ritmo

- a circulação capilar: quantidade de sangue no cérebro e circulação do sangue na mão

- a pressão do sangue

- a temperatura corporal: periférica e central, esta avaliada na axila e no reto

- a respiração: quantidade de movimentos respiratórios, forma da respiração, quantidade de ar utilizado, composição química do gás expirado

- a força muscular: atividade automática e voluntária do sistema neuromuscular, sendo nesta avaliada a influência de um trabalho intelectual curto, bem como do prolongado

- as trocas nutritivas: avaliadas através da secreção urinária, do peso e da ingestão de alimento.

Os autores não só realizaram e relataram seus próprios experimentos com rigor mitológico, como sistematizaram a literatura existente na França, Alemanha, Itália, Estados Unidos e Suíça, com o objetivo de prestar serviço aos psicólogos, geralmente, segundo os autores, muito pouco familiarizados com a psicofisiologia.

Os efeitos observados estão na ordem das modificações mais ou menos relevantes em funções fisiológicas mais importantes do organismo, como a circulação do sangue, a respiração, a 
temperatura do corpo, alteração nas trocas nutritivas do organismo e a força muscular. Um certo número destas modificações é produzido por um trabalho intelectual muito curto e outros são observados após um trabalho prolongado e intenso. Os autores concluem pela forte relação entre atividade intelectual e sua repercussão sobre o organismo, que variam quanto à natureza tanto do trabalho intelectual quanto da função fisiológica estudada. Observam ainda analogia dos efeitos; de aceleração cardíaca após um trabalho curto, bem como uma lenhificação do ritmo cardíaco durante um trabalho longo; os mesmos efeitos se repetem com relação ao pulso, aos vasos sangüíneos da mão, à função respiratória, e à força muscular. Parece então que, para um certo número de funções fisiológicas, um trabalho intelectual curto produz certas modificações, e um trabalho intelectual prolongado produz modificações opostas às precedentes.

A segunda palie, "Efeitos psicológicos do trabalho intelectual", é composta por nove capítulos, sendo um introdutório, denominado "Generalidades", onde são tecidas considerações gerais sobre a metodologia a ser utilizada e um conclusivo, onde os autores fazem comparação dos diferentes métodos psicológicos para estudar a fadiga intelectual.

Do segundo ao quarto capítulos, são relatadas pesquisas em laboratórios. No Laboratório de Psicologia de Kraepelin, em Heidelberg, na Alemanha, foram realizadas as seguintes provas: contagem de letras em um texto impresso, adição de números, escrita sem ditado, leitura em voz alta, memória de números e memória de sílabas. No segundo capítulo, analisam a influência das pausas de repouso, do tempo de reação sobre a velocidade das somas e sobre a memória de números; e, no terceiro, a influência do trabalho intelectual sobre o tempo de reação, sobre a velocidade das adições e sobre a memória de números.

Do quinto ao oitavo capítulos, experiências nas escolas, são apresentadas pesquisas realizadas utilizando o método do ditado, o método dos cálculos e o método da memória de números, incluindo o método de Ebbinghaus e o método da sensibilidade táctil.

Binet e Henri concluem que as pesquisas sobre os efeitos psicológicos do trabalho intelectual não são ainda definitivos e, portanto, sem repercussão de ordem prática para as escolas.

No último capítulo, os autores, após resumirem os principais resultados dos diferentes estudos descritos, delineiam o percurso que deve ser seguido para esclarecer esta problemática. Inicialmente, é necessário estudar mais metodicamente e mais profundamente os efeitos do trabalho intelectual sobre as diferentes funções do corpo e do espírito, vez que muitos pontos estão ainda aflorando, e estabelecer relações recíprocas entre todos estes estudos, vez que cada um deles foi realizado por um autor que, após ter escolhido seu assunto, delimitou-o com o maior cuidado e estudou os efeitos do trabalho intelectual sobre uma única função, e com um único método, o que não os impediu de tirar suas conclusões gerais sobre a "higiene do espírito". É preciso, portanto, retomar a questão e realizar um estudo global, a despeito das dificuldades práticas que podem se apresentar, uma vez que é necessário não apenas conhecer todos os sinais físicos e mentais da fadiga intelectual, mas também saber em qual momento algum deles se manifesta e qual é o seu valor. É necessário ainda determinar a relação entre as alterações fisiológicas entre si, bem como entre estas e as alterações psicológicas. Conhecer o valor de cada sinal de fadiga é saber qual o grau de fadiga que ele indica, é medir a fadiga. É necessário, então acompanhar, num mesmo grupo de indivíduos, todos os efeitos do trabalho intelectual, notando, para cada efeito, seu modo e seu momento de produção.

Cumprida esta etapa, será necessário então definir com precisão o que é excesso de trabalho. 
O excesso de trabalho é uma fadiga especial, de uma gravidade excepcional, um estado de fadiga crônica, uma fadiga patológica. É fácil apresentar definições deste gênero. Mesmo que elas sejam exatas, no sentido de que repousam sobre uma distinção muito legítima entre a fadiga normal e sadia e a fadiga insalubre. Deve-se evitar, tanto quanto possível, as definições muito vagas, porque elas deixam em suspense a questão de saber como se reconhece o excesso de trabalho intelectual, e o quanto se necessita de desordens físicas e morais para o constituir, questão prática de primeira linha. Nunca, na Academia de Medicina, nem fora dela, se pensou, nem se discutiu seriamente sobre este ponto.

Para resolver experimentalmente esta questão é preciso subdividi-Ia em duas partes distintas: uma primeira pesquisa deverá ser feita com os alunos de escolas e liceus para determinar qual é, entre eles, a velocidade de reparação da fadiga, ou em outros termos, ao fim de quanto tempo os sinais da fadiga que eles apresentaram foram dissipados, como estes alunos repousam, quais são as circunstâncias que favorecem ou que atrapalham este repouso. Uma segunda pesquisa deverá se propor a determinar qual é a velocidade de reparação que, após a idade escolar, deve ser considerada como normal e a partir de qual ponto instala-se uma patologia em conseqüência da fadiga excessiva.

Para os autores estava ainda longe o momento em que seria possível tratar cientificamente o excesso de trabalho intelectual. A questão, que parecia de fácil resolução, estava em 1889, fora de alcance. Na avaliação dos autores, em realidade, eles se aproximaram do objetivo porque dissiparam ilusões e mostraram qual é o estado exato da questão, e se tornaram cientes do que necessitava ser feito: testaram a maioria dos métodos que deveriam ser empregados, conheceram as causas de erro bem como suas vantagens.

Ao concluir o livro os autores expressam o desejo de que a administração francesa se convença que problemas pedagógicos não serão resolvidos pela simples discussão, pelos discursos e torneios oratórios, de que o melhor de tudo é realizar pesquisas de Psicologia Experimental nas escolas.

A leitura deste trabalho de Binet e Henri, nos dá uma sensação de extrema atualidade. É evidente uma preocupação com a qualidade do trabalho escolar, com o embasamento científico de todas as decisões tomadas na escola: seja na definição do currículo, da duração das aulas, do recreio, na ordenação do horário escolar, na alimentação, de condições de aeração e ventilação das salas de aula, na importância das atividades físicas. Além disso, é também evidente uma preocupação metodológica: de avaliar e criticar todos os estudos realizados; de insistir na necessidade vital de definir operacionalmente todos os termos utilizados; de buscar transmitir com a maior clareza todas as condições de realização das pesquisas relatadas, que chegam até a dar receita do pão utilizado num dos experimentos. E a pergunta que fica é: desde este trabalho, de quanto efetivamente nos adiantamos?

Nádia Maria Dourado Rocha Faculdade Ruy Barbosa Endereço: Rua General Labatut, 462. apto 304 Barris. Salvador - Bahia. CEP 40076-100 